\title{
The Influence of Fermentation on the Content of Alkylresorcinols and Lignans in Plant Products
}

\author{
Elena Bartkiene ${ }^{*, 1}$, Erika Skabeikyte ${ }^{1}$, Vita Krungleviciute ${ }^{1}$, Ida Jakobsone ${ }^{2}$, Natalija Bobere ${ }^{2,3}$, \\ Vadims Bartkevics ${ }^{2,3}$ and Grazina Juodeikiene ${ }^{4}$ \\ ${ }^{1}$ Lithuanian University of Health Sciences, Tilzes str. 18, 47181 Kaunas, Lithuania \\ ${ }^{2}$ Faculty of Chemistry, University of Latvia, Kr. Valdemara iela 48, LV-1013 Riga, Latvia \\ ${ }^{3}$ Laboratory of Food and Environmental Investigations, Institute of Food Safety, Animal Health and Environment, \\ Lejupes iela 3, LV-1076 Riga, Latvia \\ ${ }^{4}$ Kaunas University of Technology, Radvilenu str. 19, 50254 Kaunas, Lithuania
}

\begin{abstract}
The aim of this study was to evaluate the influence of solid state fermentation (SSF) and submerged fermentation (SmF) with bacteriocin-like inhibitory substances (BLIS) producing lactic acid bacteria (LAB) (Pediococcus acidilactici, Lactobacillus sakei and Pediococcus pentosaceus) on the content of alkylresorcinols (ARs) and lignans in plant products (barley bran, pea fiber, and lupine seeds).

Lignans analysis was performed by HPLC-MS/MS, and alkylresorcinols content was evaluated by GC/MS.

We found that with the experimentally tested LAB, under SSF conditions more organic acids were produced and in most cases a higher count of the LAB was found in SSF samples, compared to the SmF samples.

The matairesinol content was increased by using fermentation (from 7.9 to $35.4 \%$ in pea fiber, from 33.2 to $81.5 \%$ in lupine seeds, and from 5.9 to $74.9 \%$ in barley bran), and in most cases a higher content of matairesinol was found in the SSF samples. The content of secoisolariciresinol in the fermented samples was found to be higher, in comparison to the untreated samples. It was found that the total lignans content in the pea fiber had a strong correlation with the amylase activity $(\mathrm{R}=0.7908 ; \mathrm{P}=0.0177)$.

Our results suggested that the total ARs content in pea fiber, lupine seeds, and barley bran was $267 \mu \mathrm{g} / \mathrm{g} ; 1757 \mu \mathrm{g} / \mathrm{g}$, and $1488 \mu \mathrm{g} / \mathrm{g}$, respectively, and by using the LAB fermentation, the ARs content was reduced by 40 to $73 \%$, by 10 to $77 \%$, and by 24 to $74 \%$, respectively.

We conclude that by using the LAB fermentation, the concentration of lignans in plant products could be increased, but the ARs content could be reduced, and the proper conditions should be selected for the fermentation, in order to prevent possible losses of these biologically active compounds.
\end{abstract}

Keywords: alkylresorcinols, lactic acid bacteria, lignans, fermentation, plant products.

\section{INTRODUCTION}

The primary role of diet is to provide enough nutrients to meet metabolic requirements, while giving the consumer a feeling of satisfaction and well-being [1]. The food industry is facing the challenge of developing new food products with special health-enhancing characteristics, since the beneficial effects of healthy diet on the quality of life are widely recognized. Such products are created in response to an aging population, increasing health care costs, consumer interest in functional foods, and food technology advances. These functional materials come from a wide variety of plant

*Address correspondence to these authors at the Lithuanian University of Health Sciences, Tilzes str. 18, 47181 Kaunas, Lithuania;

Tel: +370 60135837; Fax: +370 37 300152; E-mail: elena.bartkiene@lva.lt sources which provide important nutraceutical components that may be used in food systems [2].

Bran, a byproduct of the milling industry, is yet to be efficiently utilized for human consumption [3]. Numerous epidemiological studies have shown that diets low in fat and rich in complex carbohydrates from vegetables, fruits, and grains are associated with a decreased risk of chronic diseases [4]. International epidemiological comparisons have linked the semi-vegetarian diet in some Asian countries with reduced incidence of these diseases (i.e. the major hormonedependent cancers, colon cancer, and coronary heart disease), indicating that some non-nutrient compounds in this diet may contribute to homeostasis and thus have a role in the maintenance of health. One of these non-nutrient groups of compounds are lignans, detected and identified in 
human body fluids. Lignans are diphenolic compounds in plant foods, which belong to the group of phytoestrogens. Their molecular weights and structures are similar to those of steroids, implying that they could be important dietary modulators of the human hormonal system $[5,6]$. The health effects of lignans depend on both the amount consumed and the bioavailability.

Another group of biologically active compounds in plants are alkylresorcinols (ARs). Alkylresorcinols (ARs) are a group of phenolic lipids present in the outer layer of mainly whole grain rye and whole grain wheat $(>500 \mu \mathrm{g} / \mathrm{g})$ [6]. High concentrations of plasma ARs were associated with a lower incidence of distal colon cancer [8].

Also, there is a growing interest not just in using bran for human consumption, but also in the industrial exploitation of new protein sources such as plant proteins, to broaden the range and variety of foods [9].

Legumes represent, together with cereals, the main plant source of proteins in the human diet. For instance, the supplementation of wheat flour with high-protein legume flours improve the nutritional quality of baked goods [10], also lupine does not contain gluten, thus it could be used as a functional ingredient in gluten-free foods [11].

Fermentation, as a process for manufacturing foods, has traditionally been used to preserve perishable products and enhance their nutritional value. By contrast to the western countries, solid-state fermentation has been developed in eastern countries over many centuries, and is widely used in these regions [12]. Solid state fermentation are process involving microorganisms grown on solid or semi-solid substrates or supports, and is more effective than the liquid phase submerged fermentation, because lower contents of water and energy is used for products stabilisation by using dehydration. Lactic acid bacteria (LAB) including bacteriocin-like inhibitory substances (BLIS) producing strains are GRAS (General Recognized as Safe) substances. They have received significant attention as a novel approach to the control of pathogens in foods $[13,14]$. The genus Lactobacillus is a heterogeneous group of LAB with important implications in food fermentation [15]. LAB are generally accepted as beneficial to the host and their presence is directly influenced by ingestion of fermented food or probiotics [16]. Also, it is known that cereal fermentation can increase the bioavailability of biologically active compounds [17].

The aim of this study was to evaluate the influence of solid state and submerged fermentation with BLIS producing LAB on the content of alkylresorcinols and lignans in plant products (barley bran, pea fiber, and lupine seeds).

\section{MATERIALS AND METHODS}

\section{Materials}

Barley bran were obtained from Ustukiu malunas Ltd. mill (Pasvalys, Lithuania), the blue lupine seeds (Lupinus angustifolius L.) with low alkaloid content $(<0.1 \%)$ were obtained from the Lithuanian Institute of Agriculture (Voke, Lithuania) in 2013, pea fiber was obtained from $M$ plant Ltd. (Germany). Lupine seeds were ground and the wholemeal was used for fermentation. The Pediococcus acidilactici, Lactobacillus sakei and Pediococcus pentosaceus strains previously isolated from spontaneous rye sourdough [18] were stored at $-70^{\circ} \mathrm{C}$ and cultured at $30^{\circ} \mathrm{C}$ temperature for 48 h in MRS broth (CM0359, Oxoid Ltd., Hampshire, UK) with the addition of $40 \mathrm{mmol} / \mathrm{L}$ fructose and $20 \mathrm{mmol} / \mathrm{L}$ maltose prior to use.

\section{Fermentation of the Plant Products}

The fermentation of plant products was performed with multiplied Pediococcus acidilactici, Lactobacillus sakei, and Pediococcus pentosaceus strains (2\% pure LAB from cereal / water mass). Water content was calculated with reference to moisture content of the raw materials, water absorption capacity and required humidity of the end product for solid state fermentation (SSF) was $450 \mathrm{~g} / \mathrm{kg}$, and for submerged fermentation (SMF) it was $650 \mathrm{~g} / \mathrm{kg}$. Fermentation was carried out for 48 hours at optimal temperatures for LAB cultivation: $32{ }^{\circ} \mathrm{C}(P$. acidilactici $), 35{ }^{\circ} \mathrm{C}$ (P. pentosaceus) and $30{ }^{\circ} \mathrm{C}$ (L. sakei).

\section{Determination of $\mathrm{pH}$, Total Titratable Acidity (TTA), and LAB Count in Fermented Plant Products}

The $\mathrm{pH}$ value was measured and recorded by a $\mathrm{pH}$ electrode ( $P P-15$, Sartorius, Goettingen, Germany). The total titratable acidity (TTA) was determined on $10 \mathrm{~g}$ of a sample homogenized with $90 \mathrm{~mL}$ of distilled water and expressed as the volume $(\mathrm{mL})$ of $0.1 \mathrm{M} \mathrm{NaOH}$ to get a $\mathrm{pH}$ of 8.2 (total titratable titratable.acidity (TTA) assessed in Neiman degrees, $\left.\left({ }^{\circ} \mathrm{N}\right)\right)$.

The vitality of LAB in SSF and SmF plant products was evaluated. A $10 \mathrm{~g}$ of a sample was homogenised with $90 \mathrm{~mL}$ of saline $(0.9 \%$ aqueous $\mathrm{NaCl})$. The suspension was diluted, and the $10^{-4}$ and $10^{-8}$ solutions were inoculated on MRS agar. The plates were incubated under anaerobic conditions at $30^{\circ} \mathrm{C}$ for $72 \mathrm{~h}$. After incubation, the LAB cell number was expressed as colony-forming units per gram (cfu/g). Five replicates per treatment were prepared.

\section{Determination of Amylase Activity}

The amylase levels excreted by a single LAB in plantderived media were determined by the starch-iodine method described by Nguyen et al. (2002) [19]. One unit of $\alpha$ amylase activity (1 AU) was defined as the amount of enzyme that catalyzes the hydrolysis of $1 \mathrm{~g}$ of soluble starch to dextrins over $10 \mathrm{~min}$. at $30^{\circ} \mathrm{C}$ temperature.

\section{The Analysis of Lignans in Fermented Cereal by- Products}

Samples of defatted ( $n$-hexane (for GC), $5 \mathrm{~mL}$ for $2 \mathrm{~h}$ at room temperature $)$ plant samples $(0.5 \mathrm{~g})$ were incubated with $12 \mathrm{~mL}$ of $0.3 \mathrm{M}$ sodium hydroxide in methanol/water $(70 / 30$, $\mathrm{v} / \mathrm{v}$ ) for $1 \mathrm{~h}$ at $60^{\circ} \mathrm{C}$. After hydrolysis, the hydrolysate was neutralised with glacial acetic acid and centrifuged. An aliquot of $0.5 \mathrm{~mL}$ was evaporated to dryness, dissolved in 3 $\mathrm{mL}$ of sodium acetate buffer (0.1M, pH 5.0) with $400 \mu \mathrm{L}$ of $\beta$-glucuronidase/sulfatase enzyme (from Helix pomatia), and incubated overnight at $37^{\circ} \mathrm{C}$. The enzymatic hydrolysate was extracted twice with $3 \mathrm{~mL}$ of diethyl ether and the two 
organic phases were combined and evaporated to dryness (under nitrogen with gentle heating, $\max 55^{\circ} \mathrm{C}$, on a water bath) [20]. The dried sample was redissolved in $0.5 \mathrm{~mL}$ of methanol [21]. The $\beta$-glucuronidase/sulfatase enzymes (type $\mathrm{H} 2$, from Helix Pomatia, $11400 \mathrm{U} / \mathrm{mL}$ of $\beta$-glucuronidase and $3290 \mathrm{U} / \mathrm{mL}$ of sulfatase) were purchased from SigmaAldrich.

The HPLC-MS/MS analysis was performed on an Alliance Module 2695 (Waters, USA) with separation on a Discovery C18 column $(50 \mathrm{~mm} \times 3.0 \mathrm{~mm}$ i. d., $5 \mu \mathrm{m})$ (Supelco, Germany). The mobile phase consisted of $0.5 \%$ acetic acid (HAc) in water and $0.5 \%$ acetic acid in methanol. Detection was performed with a Quattro Premier XE (Waters, UK) employing an electrospray ionization source. For detection, the characteristic precursor and product ions were combined: secoisolariciresinol $(\mathrm{m} / \mathrm{z} 361.2>\mathrm{m} / \mathrm{z}$ 165.0), matairesinol $(\mathrm{m} / \mathrm{z} 357.1>\mathrm{m} / \mathrm{z}$ 82.7). Analytes were quantified by the standard addition method [22].

\section{Methodology for the Determination of Alkylresorcinols}

Plant material samples were placed in $50 \mathrm{~mL}$ tubes and extracted by continuous shaking for $24 \mathrm{~h}$ at room temperature $\left(20^{\circ} \mathrm{C}\right.$, or rotation), with $40 \mathrm{~mL}$ of ethyl acetate containing $0.5 \mathrm{mg}$ (or $0.500 \mu \mathrm{g} / \mathrm{mL} \rightarrow 200 \mu \mathrm{L}$ ) of methyl behenate internal standard and centrifuged for $10 \mathrm{~min}$ at $1500 \mathrm{~g}(\sim 6000 \mathrm{rpm}, \mathrm{r}=4 \mathrm{~cm})$. Portions $(4 \mathrm{~mL})$ of the extract were transferred to $5 \mathrm{~mL}$ test tubes and then dried by evaporation in vacuo using a centrifuge evaporator for 40 min. Ethyl acetate $(200 \mu \mathrm{L})$ was added and the samples were mixed and filtered through $0.45 \mu \mathrm{m}$ (GHP Acrodisc) filters, and then transferred to GC vials for the analysis [22-25].

The GC/MS analyses were performed on an HP 5890 II gas chromatograph coupled to a TRIO-1000 mass spectrometer with a LAB-BASE data system (version R2.10; Fision Instruments, UK). The separation was performed on a BP-5-fused silica capillary column (5\% phenylmethylpolysiloxane; length $25 \mathrm{~m}$, inner diameter $330 \mu \mathrm{m}$, film thickness $0.25 \mu \mathrm{m}$; SGE Inc, Australia) with the following temperature programme: $60^{\circ} \mathrm{C}(0 \mathrm{~min}), 17.3^{\circ} \mathrm{C}(1$ $\min .), 320^{\circ} \mathrm{C}$ (45 min.). The injector and interface-heating temperatures were 250 and $330^{\circ} \mathrm{C}$, respectively. The column flow rate was $1.8 \mathrm{~mL} / \mathrm{min}$. The EI mass spectra were recorded at $70 \mathrm{eV}$, and the ion source temperature was $250^{\circ} \mathrm{C}$. The spectra were scanned in the $\mathrm{m} / \mathrm{z}$ range of $50-500$ at $1 \mathrm{scan} / \mathrm{s}$. At least two scans were recorded during the retention time of each peak to check the purity and homogeneity of the peak.

For quantitative analysis, a $1.0 \mu \mathrm{L}$ portion of the AR extract with or without silylation was injected into the same BP-5 capillary column (or HP-5 capillary column; $30 \mathrm{~m} \times$ $0.25 \mathrm{~mm}$ ID $\times 0.25 \mu \mathrm{m})$ fitted in an HP 6890 gas chromatograph (Hewlett-Packard, USA) with a FID detector. The injector and detector temperatures were 325 and $350^{\circ} \mathrm{C}$, respectively. Helium was used as carrier gas at an inlet pressure of 0.65 bar and with a column flow rate of 1.5 $\mathrm{mL} / \mathrm{min}$, and the split ratio was 1:10. A pulsed split programme was used, with 1 bar pressure for the first minute of the temperature programme. Separation was performed under the following temperature programme: $120^{\circ} \mathrm{C}(0$ $\min .), 200^{\circ} \mathrm{C}(5 \mathrm{~min}),. 320^{\circ} \mathrm{C}(20 \mathrm{~min}),. 320^{\circ} \mathrm{C}(35 \mathrm{~min}$. $)$.
The data was processed using Chromeleon software, version 4.3. Separation was performed under a modified temperature program for speeding up the analysis: $250^{\circ} \mathrm{C}(0 \mathrm{~min}$. $), 320^{\circ} \mathrm{C}$ (20 min.), $320^{\circ} \mathrm{C}(22 \mathrm{~min}),. 330^{\circ} \mathrm{C}(30 \mathrm{~min}$.).

\section{Statistical Analysis}

All analytical experiments were carried out in triplicate. The data were subjected to analysis of variance (ANOVA) using statistical package SPSS for Windows (Ver.15.0, SPSS Inc., Chicago, IL, USA, 2006). The calculated mean values were compared using Duncan's multiple range test with significance defined at $P \leq 0.05$.

\section{RESULTS AND DISCUSSION}

\section{The pH Values, Total Titratable Acidity (TTA), and Lactic Acid Bacteria Count in Fermented Plant Products}

The $\mathrm{pH}$, total titratable acidity (TTA), and LAB count in fermented plant products are presented in Table $\mathbf{1}$. Regardless of the used LAB, the $\mathrm{pH}$ values were lower in all SSF samples, in comparison to the SmF samples. The highest $\mathrm{pH}$ value was found in fermented lupine samples (an average 5.52 in SmF, an average 5.32 in SSF). This could be influenced by the proteineous substrate used for fermentation, and proteolysis during the process. Also, in SSF samples the production of organic acids was higher, and TTA was also higher in comparison to SmF. The highest TTA was found in SSF with $L$. sakei and $P$. pentosaceus barley bran ( 4.7 and $4.8^{\circ} \mathrm{N}$, respectively). In most cases count of the LAB was found higher in SSF samples, in comparison to the SmF samples. This fact could have an impact on the formation of higher amounts of organic acids in the samples. During the comparison of different plant substrates, the lowest $\mathrm{pH}$, and the highest TTA was found in barley bran, compared to pea fiber and lupine seed samples. $\mathrm{LAB}$ count in fermented samples was foud not significantly different. Conversion of carbohydrates to lactate by the LAB may well be considered as the most important fermentation process employed in the fermentation of these plant materials. According to our results, SSF was more effective for this conversion than $\mathrm{SmF}$.

\section{The Amylase Levels Excreted by Single LAB in Media of Plant Origin}

The amylase activities (AU/g) excreted by a single LAB in different substrates are presented in Table 2 . The highest excreted amylase activity in pea substrate was found in submerged conditions by $P$. pentosaceus $(213.8 \mathrm{AU} / \mathrm{g}$ ). In lupine seeds and barley bran media the highest amylase levels were found excreted under solid state conditions by $L$. sakei and P. pentosaceus, at $239.1 \mathrm{AU} / \mathrm{g}$ and $339.4 \mathrm{AU} / \mathrm{g}$, respectively. Semi-solid-state fermentation was adopted in the case of certain amylolytic bacteria that prefer to grow at higher moisture level [26]. Our experiments also indicated that amylase activity excreted by LAB depended on the substrate.

Amylases are a group of hydrolases that can specifically cleave the $O$-glycosidic bonds in starch [27]. The drop in $\mathrm{pH}$ associated with acid production could cause an increase in the activity of amylases in the fermented products [28]. The 
Table 1. The pH values, total titratable acidity (TTA) $\left({ }^{\circ} \mathrm{N}\right)$, and lactic acid bacteria (LAB) (cfu/g) in fermented plant products.

\begin{tabular}{|c|c|c|c|c|c|c|}
\hline \multirow{2}{*}{ Samples } & \multicolumn{3}{|c|}{ Submerged fermented (SmF) } & \multicolumn{3}{|c|}{ Solid state fermented (SSF) } \\
\hline & \multicolumn{6}{|c|}{ pH } \\
\hline Pea fiber & $5.02 \pm 0.10$ & $4.87 \pm 0.09$ & $4.79 \pm 0.09$ & $4.84 \pm 0.09$ & $4.48 \pm 0.03$ & $4.45 \pm 0.08$ \\
\hline Lupine seeds & $5.66 \pm 0.11$ & $5.54 \pm 0.10$ & $5.35 \pm 0.10$ & $5.40 \pm 0.11$ & $5.36 \pm 0.10$ & $5.20 \pm 0.10$ \\
\hline Barley bran & \multicolumn{6}{|c|}{ TTA } \\
\hline Pea fiber & $3.90 \pm 0.07$ & $2.40 \pm 0.02$ & $2.50 \pm 0.02$ & $4.10 \pm 0.08$ & $2.50 \pm 0.04$ & $2.60 \pm 0.05$ \\
\hline Lupine seeds & $2.10 \pm 0.04$ & $2.10 \pm 0.03$ & $2.30 \pm 0.04$ & $2.30 \pm 0.03$ & $2.30 \pm 0.02$ & $2.50 \pm 0.03$ \\
\hline Barley bran & $4.20 \pm 0.05$ & $3.50 \pm 0.02$ & $4.50 \pm 0.02$ & $4.70 \pm 0.05$ & $4.40 \pm 0.01$ & $4.80 \pm 0.02$ \\
\hline Lupine seeds & $62.3 \times 10^{7}$ & $22.5 \times 10^{8}$ & $36.9 \times 10^{7}$ & $71.6 \times 10^{8}$ & $62.5 \times 10^{8}$ & $48.6 \times 10^{8}$ \\
\hline Barley bran & $19.6 \times 10^{7}$ & $32.1 \times 10^{7}$ & $88.5 \times 10^{8}$ & $49.1 \times 10^{8}$ & $58.6 \times 10^{8}$ & $16.0 \times 10^{9}$ \\
\hline
\end{tabular}

Data are the mean $\pm \mathrm{SD}(\mathrm{n}=3)$

Ls - Lactobacillus sakei, $\mathrm{Pa}$ - Pediococcus acidilactici, $\mathrm{Pp}$ - Pediococcus pentosaceus

Table 2. Amylase activity of lactic acid bacteria (LAB) in fermented plant products.

\begin{tabular}{|c|c|c|c|c|c|c|}
\hline \multirow{2}{*}{ Samples } & \multicolumn{3}{|c|}{ Submerged fermented (SmF) } & \multicolumn{3}{c|}{ Solid state fermented (SSF) } \\
\cline { 2 - 7 } & Ls & Pa & Pp & Ls & Pa & Pp \\
\cline { 2 - 7 } & \multicolumn{3}{|c|}{ Amylase activity, AU/g } & $195.8 \pm 14.3$ & $132.2 \pm 2.6$ & $193.4 \pm 3.9$ \\
\hline \hline Pea fiber & $183.6 \pm 3.7$ & $162.1 \pm 2.4$ & $213.8 \pm 6.3$ & $239.1 \pm 6.0$ & $221.4 \pm 2.4$ \\
\hline Lupine seeds & $223.5 \pm 4.5$ & $166.2 \pm 3.3$ & $193.1 \pm 9.9$ & $272.1 \pm 2.5$ & $264.79 \pm 2.6$ & $339.4 \pm 5.8$ \\
\hline Barley bran & $211.3 \pm 4.8$ & $129.2 \pm 2.3$ & $243.6 \pm 4.6$ & & \\
\hline
\end{tabular}

Data are the mean $\pm \mathrm{SD}(\mathrm{n}=3)$

Lactobacillus sakei, $\mathrm{Pa}$ - Pediococcus acidilactici, $\mathrm{Pp}$ - Pediococcus pentosaceus

main factor regulating acidification is the amount of fermentable carbohydrates. The $\alpha$-amylase activity of flour depends on the extraction rate and quality of flour; wholemeal flour and especially the bran fraction having the highest enzyme activity [29]. Lupine contained high amounts of sugar $(5.82 \%)$ [30]. We found that amylase activity in the tested samples depended on the substrate and the LAB used, and the highest value was found in SSF with $P$. pentosaceus barley bran (339.4 AU/g).

\section{Lignan Content in Fermented and Untreated Plant Products}

The content of lignans in fermented and untreated plant products is presented in Table 3. It was found that the content of matairesinol increased in all samples after fermentation (from 7.9 to $35.4 \%$ in pea fiber, from 33.2 to $81.5 \%$ in lupine seeds, and from 5.9 to $74.9 \%$ in barley bran). In most cases the higher content of matairesinol was found in the SSF samples. Also, secoisolariciresinol content in fermented samples was found higher, in comparison with the untreated samples. The highest concentration of secoisolariciresinol was found in pea fiber and barley bran SSF with $P$. acidilactici and in lupine seeds fermented with $P$. pentosaceus $(140.3 \mu \mathrm{g} / 100 \mathrm{~g} ; 342.0 \mu \mathrm{g} / 100 \mathrm{~g}$ and 93.1 $\mu \mathrm{g} / 100 \mathrm{~g}$, respectively). It was revealed that the total lignans content in pea fiber had a significant correlation with amylase activity $(\mathrm{R}=0.7908 ; \mathrm{P}=0.0177)$. However, this correlation between amylase activity and total lignans content was not observed in lupine seeds and barley bran.

Lignans are present in a wide range of foods consumed daily in the Western world, such as flaxseed and other seeds, as well as vegetables, fruits, and beverages such as coffee, tea, and wine. Secoisolariciresinol diglucoside, a plant lignan, is metabolised to enterodiol, and then to enterolactone. Matairesinol, another plant lignan, is also metabolised to enterolactone. Other dietary enterolignan precursors include lariciresinol, pinoresinol, medioresinol, 
Table 3. Lignans content $(\mu \mathrm{g} / 100 \mathrm{~g})$ in fermented and untreated plant products.

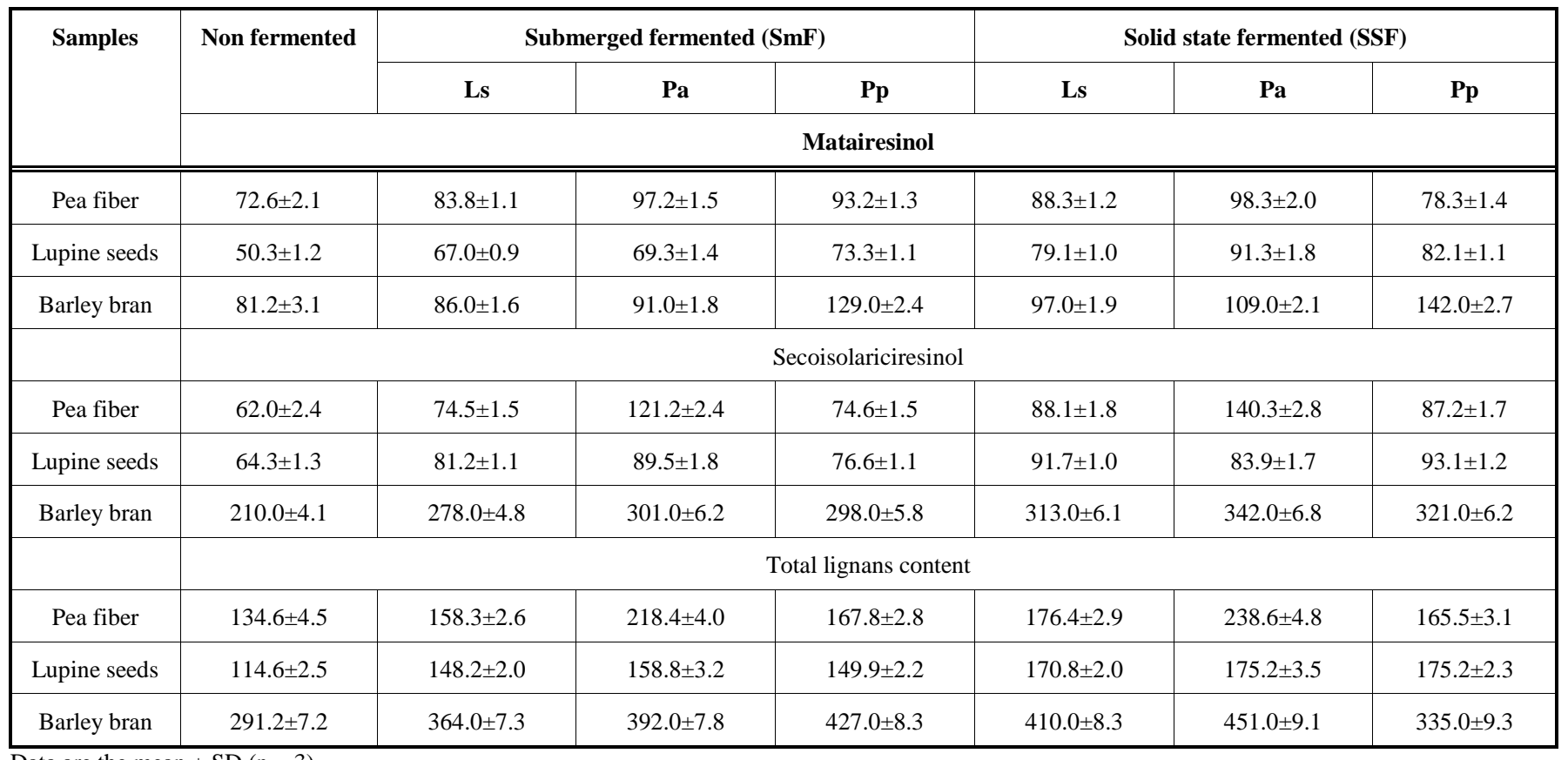

Data are the mean \pm SD $(\mathrm{n}=3)$

Lactobacillus sakei, $\mathrm{Pa}$ - Pediococcus acidilactici, $\mathrm{Pp}$ - Pediococcus pentosaceus

syringaresinol, arctigenin and sesamin. Enterolignanproducing bacteria are common, and accordingly enterolignans can be detected in the blood of most individuals. Therefore, inter-individual differences in the cell densities of the aforementioned bacteria may explain the inter-individual differences in the concentrations of enterolignan in blood [31]. Also, the quantitative relationship between non-starch polysaccharides (NSP) components and their associated lignan metabolites were determined [32]. The health effects of lignans depend on both the amount consumed and the bioavailability. Although numerous lignans have been identified, it is not known which of them are converted to enterolignans [33, 34]. For about two decades, only secoisolariciresinol and matairesinol were known to be precursors of enterolignans. Lignans are closely associated with the dietary fibre matrix of plant-derived food, thus it is possible that their composition might influence the availability of lignans. The use of LAB for the fermentation of plant materials could improve the digestibility [35] and conversion of lignans to the enterolignans.

\section{The Content of Alkylresorcinols in Fermented Plant Products}

The content of alkylresorcinols (ARs) in fermented plant products is presented in Table 4.

In most cases, fermentation decreases the ARs content in samples. Our results suggest that the total ARs content in pea fiber, lupine seeds, and barley bran is $267 \mu \mathrm{g} / \mathrm{g}, 1757 \mu \mathrm{g} / \mathrm{g}$, and $1488 \mu \mathrm{g} / \mathrm{g}$, respectively. The use of LAB fermentation reduced the ARs content by 40 to $73 \%$, by 10 to $77 \%$, and by 24 to $74 \%$, respectively.
The ARs have been found in higher plants, algae, mosses, fungi, and bacteria [36]. Different cereals have a specific relative composition of different ARs homologues (C17:0-C25:0), with a typical C17:0/C21:0 ratio of about 0.01 for durum wheat, 0.1 for wheat, and 1.0 for rye [37]. According to Ross et al. ARs are present in the outer layer of mainly whole grain rye and whole grain wheat $(>500 \mu \mathrm{g} / \mathrm{g})$ [38]. The length of the alkyl side chain of ARs varies from 13 to 27 carbon atoms [39, 40]. The side chain is usually saturated, but unsaturated and oxygenated chain analogues have also been reported [41]. The content of ARs in whole grain products is relatively high (e.g. whole grain rye crisp bread $886-1007 \mu \mathrm{g} / \mathrm{g}$; whole grain rye bread $380-707 \mu \mathrm{g} / \mathrm{g}$ ) [42].

Cereals constitute a major source of dietary carbohydrates in Western countries. However, cereals are often consumed as refined products, thereby lacking ARs and other components associated with the bran. Interest in the potential health benefits from whole grain cereals has increased in the recent years. ARs are among the bioactive components in whole grain that could play a role in the protective effect of whole grain products regarding diabetes risk [43]. We found that the highest content of ARs is present in lupine seeds $(1757 \mu \mathrm{g} / \mathrm{g})$, and special conditions for the fermentation should be selected in order to prevent possible losses of these biologically active compounds.

\section{CONCLUSION}

The LAB used in the experiment under solid state conditions produce more organic acids, and in most cases the higher count of the LAB was found in SSF samples, 
Table 4. Alkylresorcinols content $(\mu \mathrm{g} / \mathrm{g})$ in fermented plant products.

\begin{tabular}{|c|c|c|c|c|c|c|c|}
\hline \multirow[t]{2}{*}{ Samples } & $\begin{array}{c}\text { Non } \\
\text { fermented }\end{array}$ & \multicolumn{3}{|c|}{ Submerged fermented (SmF) } & \multicolumn{3}{|c|}{ Solid state fermented (SSF) } \\
\hline & \multicolumn{7}{|c|}{ C15:0 } \\
\hline Pea fiber & $200 \pm 0.6$ & $22 \pm 0.8$ & $25 \pm 0.3$ & $32 \pm 0,5$ & $22 \pm 0.4$ & $30 \pm 0.3$ & $24 \pm 0.9$ \\
\hline Lupine seeds & $1134 \pm 0.2$ & $423 \pm 0.8$ & $200 \pm 0.2$ & $1028 \pm 0.2$ & $444 \pm 0.7$ & $223 \pm 0.2$ & $1483 \pm 0.3$ \\
\hline Barley bran & \multicolumn{7}{|c|}{ C19:0 } \\
\hline Pea fiber & $60 \pm 0.5$ & $55 \pm 0.3$ & $35 \pm 0.8$ & $25 \pm 0.3$ & $44 \pm 0.2$ & $51 \pm 0.6$ & $21 \pm 0.8$ \\
\hline Lupine seeds & $203 \pm 0.6$ & $42 \pm 0.2$ & $88 \pm 0.3$ & $113 \pm 0.7$ & $149 \pm 0.4$ & $200 \pm 0.5$ & $34 \pm 0.1$ \\
\hline Barley bran & $352 \pm 0.9$ & $340 \pm 0.2$ & $388 \pm 0.5$ & $295 \pm 0.4$ & $213 \pm 0.4$ & $169 \pm 0.7$ & $68 \pm 0.4$ \\
\hline Lupine seeds & $23 \pm 0.2$ & $22 \pm 0.5$ & $102 \pm 0.1$ & $45 \pm 0.2$ & $58 \pm 0.3$ & $52 \pm 0.2$ & $21 \pm 0.2$ \\
\hline \multirow[t]{2}{*}{ Barley bran } & $779 \pm 0.2$ & $370 \pm 0.5$ & $574 \pm 0.1$ & $436 \pm 0.2$ & $288 \pm 0.7$ & $277 \pm 0.5$ & $221 \pm 0.6$ \\
\hline & \multicolumn{7}{|c|}{$\mathrm{C} 23: 0$} \\
\hline Pea fiber & $4 \pm 0.3$ & $18 \pm 0.4$ & $23 \pm 0.5$ & $21 \pm 0.6$ & $25 \pm 0.3$ & $20 \pm 0.2$ & $11 \pm 0.1$ \\
\hline Lupine seeds & $397 \pm 0.9$ & $36 \pm 0.9$ & $18 \pm 0.6$ & $142 \pm 0.8$ & $93 \pm 0.4$ & $57 \pm 0.6$ & $45 \pm 0.4$ \\
\hline \multirow[t]{2}{*}{ Barley bran } & $335 \pm 0.4$ & $276 \pm 0.3$ & $48 \pm 0.4$ & $236 \pm 0.2$ & $158 \pm 0.7$ & $6 \pm 0.8$ & $92 \pm 0.4$ \\
\hline & \multicolumn{7}{|c|}{ Total alkylresorcinols content } \\
\hline
\end{tabular}

Data are the mean \pm SD $(\mathrm{n}=3)$

Lactobacillus sakei, $\mathrm{Pa}-$ Pediococcus acidilactici, $\mathrm{Pp}$ - Pediococcus pentosaceus

compared to SmF. Also, the amount of amylase excreated by $\mathrm{LAB}$ in our experiments depended on the specific substrate.

Matairesinol content in plant products was increased by the fermentation (by 7.9 to $35.4 \%$ in pea fiber, by 33.2 to $81.5 \%$ in lupine seeds, and by 5.9 to $74.9 \%$ in barley bran), and in most cases the higher content of matairesinol was found in SSF samples. The secoisolariciresinol content in fermented samples was found to be higher, compared to untreated samples. It was found that the total lignans content in pea fiber correlates significantly with the amylase activity $(\mathrm{R}=0.7908 ; \mathrm{P}=0.0177)$. However, no correlation between the amylase activity and total lignans content was revealed in lupine seeds and barley bran.

Our results indicate that the total ARs content in pea fiber, lupine seeds, and barley bran was $267 \mu \mathrm{g} / \mathrm{g} ; 1757 \mu \mathrm{g} / \mathrm{g}$, and $1488 \mu \mathrm{g} / \mathrm{g}$, respectively, the ARs content was reduced by using LAB fermentation by 40 to $73 \%$, by 10 to $77 \%$, and by 24 to $74 \%$, respectively.
We concluded that the lignans content in plant products could be increased by using the LAB fermentation, while the ARs content could be reduced, and suitable conditions should be selected for fermentation to prevent the losses of these biologically active compounds.

\section{CONFLICT OF INTEREST}

The authors confirm that no conflicts of interest are associated with this article.

\section{REFERENCES}

[1] Granato D, Branco GF, Nazzaro F, et al. Functional foods and nondairy probiotic food development: trends, concepts, and products. Compr Rev Food Sci 2010; 3: 292-302. doi:10.1111/j. 1541-4337.2010.00110.x

[2] Lebesi DM, Tzia C. Effect of the addition of different dietary fiber and edible cereal bran sources on the baking and sensory characteristics of cupcakes. Food Bioprocess Technol 2011; 4: 71022. doi:10.1007/s11947-009-0181-3

[3] Kaur G, Sharma S, Nagi HPS, Basharat ND. Functional properties of pasta enriched with variable cereal brans. J Food Sci Technol 2012; 49: 467-74. doi: 10.1007/s13197-011-0294-3 
[4] Rohan TE, Jain MG, Howe GR, Miller AB. Dietary folate consumption and breast cancer risk. J Natl Cancer Inst 2000; 92: 266-9. doi: 10.1093/jnci/92.3.266

[5] Adlercreutz H. Western diet and Western diseases: some hormonal and biochemical mechanisms and associations. Scand J Clin Lab Invest 1990; 50: 2013-23. doi:10.1080/00365519009085798

[6] Del Rio D, Rodriguez-Mateos A, Spencer JPE, Tognolini M, Borges G, Crozier A. Dietary (Poly)Phenolics In Human Health: Structures, Bioavailability, And Evidence Of Protective Effects Against Chronic Diseases. Antioxid Redox Signal 2013; 18: 181892. doi:10.1089/ars.2012.4581

[7] Andersson AAM, Landberg R, Söderman T, et al. Effects of alkylresorcinols on volume and structure of yeast-leavened bread. $\mathrm{J}$ Sci Food Agric 2011; 91: 226-32. doi:10.1002/jsfa.4174

[8] Kyrø C, Olsen A, Landberg R, et al. Plasma alkylresorcinols, biomarkers of whole-grain wheat and rye intake, and incidence of colorectal cancer. JNCI J Natl Cancer Inst, 2014; 106(1): 1-9. doi:10.1093/jnci/djt352

[9] Guillamon E, Cuadrado C, Pedrosa MM, et al. Breadmaking properties of wheat flour supplemented with thermally processed hypoallergenic lupine flour. Span J Agric Res 2010; 8: 100-8. doi:10.5424/sjar/2010081-1148

[10] Gomez M, Oliete B, Rosell CM, Pando V, Fernandez E. Studies on cake quality made of wheat-chickpea flour blends. Food Sci Technol 2008; 41:1701-9. doi:10.1016/j.1wt.2007.11.024

[11] Scarafoni A, Ronchi A, Duranti M. A realtime PCR method for the detection and quantification of lupin flour in wheat flour-based matrices. Food Chem 2009; 115:1088-93. doi:10.1016/j.foodchem. 2008.12.087

[12] Udo LJ. Solid-state fermentation - are there any biotechnological advantages? Curr Opin Microbiol 2005; 8: 301-6. doi: 10.1016/j.mib.2005.04.006

[13] Settani L, Massitti O, Van Sinderen D, Corsetti A. In situ activity of a bacteriocin - producing Lactococcus lactis strain. Influence on the interactions between lactic acid bacteria during sourdough fermentation. J Appl Microbiol 2005; 99: 670-81. doi:10.1111/j.1365-2672.2005.02647.x

[14] Narbutaite V, Fernandez A, Horn N, Juodeikiene G, Narbad A. Influence of baking enzymes on antimicrobial activity of five bacteriocin-like inhibitory substances produced by lactic acid bacteria isolated from Lithuanian sourdoughs. Lett Appl Microbiol 2008; 47: 555-60. doi: 10.1111/j.1472-765X.2008. 02466.x

[15] Giraffa G, Chanishvili N, Widyastuti Y. Importance of lactobacilli in food and feed biotechnology. Res Microbiol 2010; 161: 480-7. doi: 10.1016/j.resmic.2010.03.001

[16] Albesharat R, Ehrmann MA, Korakli M, Yazaji S, Vogel RF. Phenotypic and genotypic analyses of lactic acid bacteria in local fermented food, breast milk and faeces of mothers and their babies. Syst Appl Microbiol 2011; 34: 148-55. doi: 10.1016/j.syapm. 2010. 12.001 .

[17] Hole AS, Rud I, Grimmer S, Sigl S, Narvhus J, Sahlstrøm S. Improved bioavailability of dietary phenolic acids in whole grain barley and oat groat following fermentation with probiotic Lactobacillus acidophilus, Lactobacillus johnsonii, and Lactobacillus reuteri. J Agric Food Chem 2012; 60: 6369-75. doi:10.1021/ jf300410h.

[18] Digaitiene A, Hansen A, Juodeikiene G, Josephsen J. Microbial population in Lithuanian spontaneous rye sourdoughs. Ekologia i Technika 2005; 5: 193-8.

[19] Nguyen QD, Rezessy-Szabó JM, Claeyssens M, Stals I, Hoschke A. Purification and characterisation of amylolytic enzymes from thermophilic fungus Thermomyces lanuginosus strain ATCC 34626. Enzyme Microb Technol 2002; 31: 345-52. doi:10.1016/ S0141-0229(02)00128-X

[20] Mazur W. Phytoestrogens: occurrence in foods, and metabolism of lignans in man and pigs. Academic dissertation. Medical Faculty of the University of Helsinki, 2000, 140. ISBN 951-45-9154-2.

[21] Krajčová A, Schulzová V, Hajšlová B, Bjelková M. Lignans in Flaxseed. Czech J Food Sci 2009; 27: S252-5.

[22] Annica AM, Andersson MAA, Åman P, Wandel M, Frølich W. Alkylresorcinols in wheat and rye flour and bread. J Food Comp Anal 2010; 23: 794-801. doi:10.1016/j.jfca. 2010.03.012
[23] Hedkvist S. Bread volume and alkylresorcinol content in rye bread baked with high and low levels of alkylresorcinols. Swedish University of Agricultural Science, Department of Food Science 2009; vol. 261: p. 29.

[24] Ross AB, Shepherd MJ, Schupphaus M, et al. Alkylresorcinols in cereals and cereal products. J Agric Food Chem 2003; 51: 4111-8. doi: 10.1021/jf0340456

[25] Landberg R, Andersson AAM, Åman P, Kamal-Eldin A. Comparison of GC and colorimetry for the determination of Alkylresorcinol homologues in cereal grains and products. Food Chem 2009; 113: 1363-9. doi:10.1016/j.foodchem.2008.08.072

[26] Naveena BJ, Altaf M, Bhadriah K, Reddy G. Selection of medium components by Placket Burman design for the production of $\mathrm{L}(+)$ lactic acid by Lactobacillus amylophilus GV6 in SSF using wheat bran. Bioresour Technol 2005; 96: 485-90.

[27] Gard D, Kaur M. Extraction, purification and characterisation of enzyme amylase from Bacillus amyloliquefaciens. Int J Adv Eng Sci 2013; 3: e-ISSN: 2231-0347 Print-ISSN: 2231-2013.

[28] Arendt EK, Ryan LAM, Dal Bello F. Impact of sourdough on the texture of bread. Food Microbiol 2007; 24, 165-74. doi: 10.1016/j.fm.2006.07.011

[29] Martínez-Anaya MA. Associations and interactions of microorganisms in dough fermentations: effects on dough and bread characteristics. In: Kulp K. Lorenz K. (eds.). Handbook of dough fermentations. New York, Marcel Dekker Inc 2003, pp. 63-195.

[30] Erbas M, Certel M, Uslu MK. Some chemical properties of white lupin seeds (Lupinus albus L.). Food Chem 2005; 89: 341-5. doi: 10.1016/j.foodchem.2004.02.040

[31] Landete JM. Plant and mammalian lignans: a review of source, intake, metabolism, intestinal bacteria and health. Food Res Int 2012; 46: 410-24. doi:10.1016/j. foodres.2011.12.023

[32] Bartkiene E, Juodeikiene G, Basinskiene L, Liukkonen KH, Adlercreutz $\mathrm{H}$, Kluge $\mathrm{H}$. Enterolignans enterolactone and enterodiol formation from their precursors by the action of intestinal microflora and their relationship with non-starch polysaccharides in various berries and vegetables. LWT - Food Sci Technol 2011; 44: 48-53. doi:10.1016/j.1wt.2010. 06.018

[33] Smeds AL, Hakala K, Hurmerinta TT, Kortela L, Saarinen NM, Mäkelä SI. Determination of plant and enterolignans in human serum by HPLC with tandem mass spectrometric detection. J Pharma Biomed Anal 2006; 1: 898-905. doi:10.1016/j.jpba.2005. 12.036

[34] Smeds AL, Hakala K, Hurmerinta TT, Penttinen PB, Sjöholm RE, Mäkelä SI. Urinary excretion of lignans after administration of isolated plant lignans to rats: the effect of single dose and ten-days exposures. J Chromatogr B 2004; 813: 303-12. doi:10.1016/j.j chromb.2004.10.033

[35] Oyewole OA, Isah P. Locally fermented foods in nigeria and their significance to national economy: a Review. J Rec Adv Agri 2012; 1: $92-102$.

[36] Céspedes CL, Sampietro DA, Seigler DS, Rai M. CABI, Natural antioxidants and biocides from wild medicinal plants (Edited by Céspedes C L), ISBN-13: 978178064233 8, 2013; 272.

[37] Andersson U, Dey ES, Holm C, Degerman E. Rye bran alkylresorcinols suppress adipocyte lipolysis and hormonesensitive lipase activity. Mol Nutr Food Res 2011; 55: S290-3. doi:10.1002/mnfr.201100231

[38] Ross BA, Kamal-Eldin A, Jung C, Shepherd M J, Åman P. Gas chromatographic analysis of alkylresorcinols in rye (Secale cereale L) grains. J Sci Food Agric 2001; 81: 1405-11. doi:10.1002/jsfa.956

[39] Knödler M, Kaiser A, Carle R, Schieber A. Profiling of alk(en)ylresorcinols in cereals by HPLC-DAD-APcI-MSn. Anal Bioanal Chem 2008; 391: 221-8. doi:10.1007/s00216-008-1937-8

[40] Kozubek A. Cereal grain resorcinolic lipids: mono and dienic homologues are present in rye grains. Chem Phys Lipids 1995; 78: 29-35. doi: 10.1016/0009-3084(95)02480-7

[41] Kozubek A, Tyman JH. Resorcinolic lipids, the natural nonisoprenoid phenolic amphiphiles and their biological activity. Chem Rev 1999; 99: 1-26.

[42] Ross AB, Kamal-Eldin A, Aman P. Dietary alkylresorcinols: absorption, bioactivities, and possible use as biomarkers of whole- 
grain wheat- and rye-rich foods. Nutr Rev 2004; 62: 81-95. doi:10.1301/nr.2004.mar.81-95
[43]

Gibson S, Nutr R, Ashwell M, Fafn O, Van der Kamp JW. Cereal foods and health. New results and science-based nutrition guidelines. Complete Nutr 2014; 13: 26.

Received: July 22, 2014

(c) Bartkiene et al.; Licensee Bentham Open.

This is an open access article licensed under the terms of the Creative Commons Attribution Non-Commercial License (http://creativecommons.org/licenses/ by-nc/3.0/) which permits unrestricted, non-commercial use, distribution and reproduction in any medium, provided the work is properly cited. 